\title{
CORRECTION
}

\section{Correction to: Fertility in testicular cancer patients: a single-centre study in Turkey}

\author{
Mürvet Artuk Uçar ${ }^{1} \cdot$ Fatma Arikan $^{2}$ (1) · Hasan Şenol Coşkun ${ }^{3} \cdot$ Yasemin Kondak $^{1}$ - Ali Murat Tatı ${ }^{3}$. \\ Sema Sezgin Göksu ${ }^{3}$
}

Published online: 3 December 2019

(C) Japan Society of Clinical Oncology 2019

\section{Correction to: International Journal of Clinical Oncology https://doi.org/10.1007/s10147-019-01534-7}

The updated version of Table 4 of original publication and the Compliance with ethical standards are given in this correction.
"Ethics Committee for Clinical Investigations" of Akdeniz University Medical Faculty" (Date: 19.10.2018, Number: 70904504/488) and permission to use data was obtained from “Akdeniz University Hospital Chief Physician's Office.

Conflict of interest The authors have no conflicts of interest to declare or financial disclosures.

Table 4 Clinical characteristics of patients who became fathers following treatment $n=(33)$

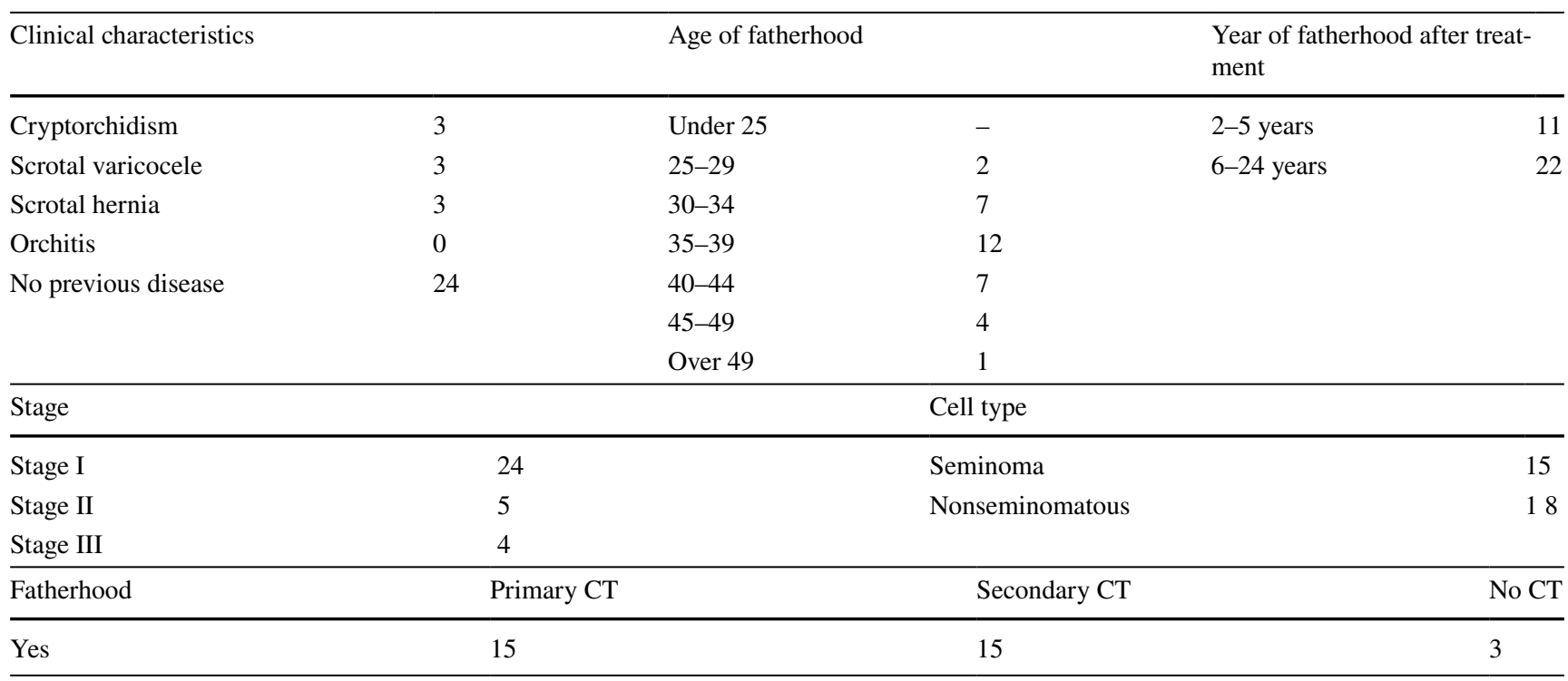

$C T$ chemotherapy

The original article can be found online at https://doi.org/10.1007/ s10147-019-01534-7.

Fatma Arikan

farikan64@gmail.com

1 Department of Medical Oncology, Akdeniz Universty Hospital, Antalya, Turkey

2 Faculty of Nursing, Akdeniz University, Antalya, Turkey

3 Department of Medical Oncology, Akdeniz University School of Medicine, Antalya, Turkey 